\title{
Game Simulation Analysis of Radical Innovation Processes of High-tech Enterprises based on WoO-EGT Model
}

\author{
Zhen ZHANG, Jintian YU
}

\begin{abstract}
An analysis of the evolution law of radical innovation process (RIP) and an identification of the RIP's influencing factors, particularly to solve the low success rates of the radical innovation of high-tech enterprises, is the focus of this study. The dynamic evolution of RIP can be explained from the perspective of market timing of innovation processes. Moreover, the key influencing factors and the impact mechanism of the process of evolution need to be identified. The window of opportunity-evolutionary game theory (WoO-EGT) model of RIP, which was built by combining WoO and EGT, was used to analyze the dynamic evolutions of the RIPs of existing and new high-tech enterprises. The three categories of RIP evolution when WoO was opened-only locking technology, only breakthrough technology, and coexistence of locking and breakthrough technologies-were determined and verified. Then, the impact mechanisms of the returns and initial proportion of breakthrough technologies on RIP evolution were dynamically and numerically simulated by Matlab. Results show that WoO is the best time for enterprises to implement RIP, and the three game results of RIP evolution of high-tech enterprises under WoO are only locking technology, only breakthrough technology, and both locking and breakthrough technologies, which occupy certain proportions in the market. Moreover, the returns of breakthrough technology play a decisive role in the evolution results of RIP, and the initial proportion of breakthrough technology affects the evolution speed of RIP. According to the research, the WoO-EGT model built in this study is feasible in dynamically analyzing the RIPs. The WoOEGT model can help overcome the deficiencies of the static model of RIP and provide new decision-making ideas and methods for analyzing the RIPs of high-tech enterprises, thus contributing to the improvement of the success rates of radical innovation.
\end{abstract}

Keywords: Evolutionary Game; High-tech Enterprises; Radical Innovation Process (RIP); Window of Opportunity (WoO)

\section{INTRODUCTION}

In the age of total innovation, radical innovation has caught enterprises' attention more than incremental innovation, especially among high-tech enterprises with rapid technological changes; in such scenarios, radical innovations are crucial in solving the technological lock-in problems of enterprises and their industries, and they are essential elements in improving the sustainable competitiveness of enterprises [1,2]. However, the success rates of the radical innovations of high-tech enterprises have continuously declined in recent years. According to statistics, among over 24000 high-tech products distributed in the market, only 15 have achieved technological breakthroughs [3]. Moreover, 47\% of these radical innovations reportedly have failed, and nearly $75 \%$ of the new products have faced failure upon launching [4]. A radical innovation process (RIP) can be described as the ability to overcome the restraints of existing technological lock-ins within the enterprise or the industry, and it is often associated with the introduction of breakthroughs through independent $R \& D$ or purchase, which then provide the products with new or improved performance in the market [5-6]. Thus, the RIPs of high-tech enterprises are expected to challenge the existing locking technologies in the market. Similar to the locking technologies in the external market, the RIP of an enterprise involves a process of dynamic evolution, which implies that the success rate of radical innovation is closely related to the timing of market entry. Furthermore, RIP is affected by the returns and initial proportion of breakthrough technologies when the opportunities tied to these technologies present themselves. Therefore, finding the opportunities for RIPs to enter the market and identifying the influencing factors of these opportunities and their impact mechanisms on the dynamic evolution of RIPs are the key elements for improving the success rates of the radical innovation of high-tech enterprises.
However, the existing research on the market timing of RIPs and the identification of their influencing factors under this timing context has paid more attention to policy system, organizational management and external investment [7-11], among others, at the institutional economic level rather than on the technological factors, such as technological returns and initial proportion of technology. In addition, by being limited to certain static methods (e.g., case analysis, Bayesian decision-making method, Malmquist productivity index, data envelope analysis (DEA), etc. [12-15]), the research on the impact mechanism of the factors affecting RIP has ignored the non-linearity and high uncertainty of RIP [16]. The existing research on RIP has also mainly analyzed the factors affecting the institutional economy, whereas the technological factors and the impact mechanism, influencing factors, and dynamic evolution of RIP have been largely ignored. To overcome the research gap, the window of opportunity-evolutionary game theory (WoOEGT) model of RIP is built by combining WoO and EGT. In particular, the dynamic evolutions of RIP of existing and new high-tech enterprises are analyzed, the results of these dynamic evolutions in the $\mathrm{WoO}$ context are obtained, and the impact mechanisms of radical technological returns and initial proportion on RIP evolution are simulated numerically in Matlab. Subsequently, countermeasures are proposed to promote RIP evolution, which is of great practical significance to improving the success rates of radical innovations of high-tech enterprises.

\section{STATE OF THE ART}

Several research results regarding the market timing of RIP and the identification of its influencing factors under the timing context have been achieved. Scholars usually conduct their analyses based on the specific situations of RIPs of high-tech enterprises. Isaksen emphasized the important role of external investment on RIP based on the existing technological lock-in effect of industrial and 
enterprise development in Norway [8]. Cecere et al. focused on technological lock-in in radical ecological innovation to analyze technological niche, enterprise strategy change, user guidance, and management regulations in a radical ecological innovation process [14]. Perra et al. attributed the success rates of radical innovations of established companies to management identity [7]. Schreyogg and Sydow proposed the implementation of RIP along with the driving mechanism formed by existing technological lock-ins [17]. Tsiapa et al. explained the positive effect of policy and economic factors on RIP during economic recovery by analyzing enterprise technological lock-in during the economic crisis of European Union (EU) [12]. The above research on the market timing of RIP and its influencing factors under the timing context has focused mainly on the institutional and economic factors and the timing of market technological lock-in (i.e., policy system, organizational management, external investment, etc.). However, the technological factors of RIP, such as the returns and initial proportion of existing locking technologies and breakthrough technologies, have been largely ignored by extant research.

The impact mechanisms of the influencing factors of RIP have been mainly derived through the following methods: literature review, case analysis, Bayesian decision-making method, Malmquist productivity index, and DEA non-parametric technology [18-22]. Cecere et al. classified the impact mechanisms of technological niche and other factors on the radical ecological innovation processes of high-tech enterprises in the form of literature review [14]. Thrane et al. analyzed the impact mechanism of cognitive framework and mediation on RIP by taking high-tech medical service enterprises in North Europe as examples [23]. Lawrence et al. studied the importance of non-market forces with radical innovation by referring to nuclear energy technology enterprises in Europe as the object [13]. The literature review and case analysis methods, which can explain the praxis of existing theories or extend their theoretical development, both belong to the category of qualitative analysis. However, qualitative analysis is highly subjective and thus reduces the scientific nature of the impact mechanism. Crouch and Farrell studied the mechanism of past experience transfer and sudden events influencing RIP by using the Bayesian decision-making method [15]. This particular method can effectively analyze the action direction of influencing factors. However, due to limitations in parametric modeling and analysis, the Bayesian decision-making method cannot easily detect the impact degree of influencing factors. Tsiapa et al. used the Malmquist and DEA methods to explain the RIPs of EU enterprises and the action mechanism of relevant policies (i.e., these methods can effectively investigate the impact degree of influencing factors). However, the empirical analysis of large volumes of data, which is characteristic of both methods, are likely only limited to the academic level, as evidenced by the inapplicability of the results among realworld heterogeneous high-tech enterprises [13]. Many scholars have also analyzed the impact mechanism of influencing factors through traditional static methods. However, the RIPs of high-tech enterprises are characterized by high uncertainty, information asymmetry, non-linearity, and constant trials and learning. The analyses of RIPs of high-tech enterprises based on static evaluation can neither expound the process of how equilibrium is reached nor detect the impact degree of influencing factors during RIP evolution.

As a potential solution to the above mentioned problems, the WoO-EGT model of RIP evolution is built by combining WoO and EGT. In particular, the dynamic evolution of RIPs of existing and new high-tech enterprises is analyzed, the evolution variables of RIPs when WoO is opened are calculated by using a replicated dynamic equation, and the mechanisms of the returns and initial proportion of breakthrough technologies that influence the evolution of RIP are dynamically simulated in Matlab [24, 25]. On this basis, countermeasures are proposed to promote the process evolution and improve the success rate of a radical innovation.

The rest of the study is structured as follows. The WoO of RIP, the basic assumptions and payoff function, the WoO-EGT model of dynamic evolution of RIP, and the intelligent simulation design by using Matlab are discussed in Section 3. The dynamic evolution law of RIP when WoO is opened and the impact mechanism of relevant factors are analyzed in Section 4. The conclusions are drawn in Section 5.

\section{MODEL BUILDING 3.1 Market Timing of RIP}

RIP is expected to replace the existing technologies in the market with new breakthrough technologies. The market timing of RIP is closely related to the evolution of existing technologies in the market. According to the A-U model and the technology life cycle theory [26], existing technologies in the market evolve through the process of germination, growth, maturity, and recession. The period called later maturity is regarded as the market timing of RIP, and it is regarded as the WoO of RIP. Given that the later-maturity period of existing technologies in the market is limited to the incremental innovation of existing locking technologies, and considering that their technological potentials have been fully mined in the growth stage, the performance of technology products will have no substantial changes in this stage [27]. However, if the breakthrough technology can be introduced to the market at this stage, then either the performance of products can be remarkably improved or new performance products may be provided, which can increase the acceptance probability of products [28]. Therefore, the later-maturity stage of existing technologies is the timing and $\mathrm{WoO}$ of RIP to enter the market.

\subsection{Basic Hypotheses and Payoff Function 3.2.1 Basic Hypotheses}

In consideration of the actual situation, five hypotheses are considered for the WoO-EGT model.

Hypothesis 1: In the WoO of RIP, high-tech enterprises can randomly choose two strategies. The first strategy is the selection of existing technologies in the market to initiate an incremental innovation process, while the second strategy is the selection of new breakthrough technologies to implement RIP. The strategy is expressed 
as $S=\left\{S_{B}, S_{L}\right\}$. The strategy combinations are shown in Tab. 1 .

Table 1 Strategy combinations of gaming

\begin{tabular}{|c|c|c|c|}
\hline \multicolumn{2}{|c|}{ Strategy } & \multicolumn{2}{c|}{ High-tech Enterprise B } \\
\cline { 2 - 4 } & Breakthrough & Locking \\
\hline \multirow{2}{*}{$\begin{array}{c}\text { High-tech } \\
\text { Enterprise A }\end{array}$} & Breakthrough & $\left(S_{B}, S_{B}\right)$ & $\left(S_{B}, S_{L}\right)$ \\
\cline { 2 - 4 } & Locking & $\left(S_{L}, S_{B}\right)$ & $\left(S_{L}, S_{L}\right)$ \\
\hline
\end{tabular}

Assume that the proportion of high-tech enterprises selecting the breakthrough strategy is $p$, and the utility function is $U^{B}$. The proportion of high-tech enterprises selecting the locking strategy is $(1-p)$, and the utility function is $U^{L}, 0 \leq p \leq 1$. Meanwhile, in consideration of the mixed strategy, the average utility when Strategy $S_{B}$ meets $S_{L}$ is $\Delta U$.

Hypothesis 2: The equilibrium in the evolutionary game is not the result of one-off selection but the process of constant trial and learning. When $U^{B}>U^{L}$, the hightech enterprise will select $S_{B}$, and vice versa.

Hypothesis 3: The members in the groups of players usually face all high-tech enterprises when making decisions. The members are assumed to undergo repeated games through random pairing.

Hypothesis 4: All players are similar after random pairing. The difference in the profits between two players can be attributed to the different action strategies only. So the game is a $2 \times 2$ symmetric game.

Hypothesis 5: The evolution result of strategy selection is an evolutionary stabilization strategy (ESS) equilibrium.

\subsubsection{Payoff Function}

Incremental innovation or radical innovation is realized on the basis of the selected locking technology or breakthrough technology to obtain returns. The returns are assumed to be $R_{j}\left(R=\left\{R_{B}, R_{L}\right\}\right)$. The cost of acquiring technology through independent $\mathrm{R} \& \mathrm{D}$, cooperative $\mathrm{R} \& \mathrm{D}$, or external purchase is $C^{1}\left(C_{j}^{1}=\left\{C_{B}^{1}, C_{L}^{1}\right\}\right)$, and the cost of excluding technology $\mathrm{R} \& \mathrm{D}$ or purchase is $C^{2}$ $\left(C_{j}^{2}=\left\{C_{B}^{2}, C_{L}^{2}\right\}\right)$. Thus, $C^{2}$ is related to market demand and output. The corresponding profit is expressed as $\pi_{j}=R_{j}-C_{j}^{1}-C_{j}^{2}\left(\pi_{j}=\left\{\pi_{B}, \pi_{L}\right\}\right)$.

\subsubsection{Relevant Parameter Settings}

The high-tech enterprises are divided into two categories, namely, existing enterprises and new high-tech enterprises. The former is regarded as always carrying out incremental innovation processes with existing locking technologies, whereas the latter has the "green hand" in the industry for never having carried out innovative processes with existing locking technologies in the industry. The relevant parameters are shown in Tab. 2 .
Table 2 Definitions of relevant parameters

\begin{tabular}{|c|l|}
\hline Symbol & \multicolumn{1}{|c|}{ Definition } \\
\hline$p_{x}$ & $\begin{array}{l}\text { Proportion of new high-tech enterprises adopting } \\
\text { breakthrough technologies }\end{array}$ \\
\hline $1-p_{x}$ & $\begin{array}{l}\text { Proportion of new high-tech enterprises adopting locking } \\
\text { technologies }\end{array}$ \\
\hline$P_{y}$ & $\begin{array}{l}\text { Proportion of existing high-tech enterprises adopting } \\
\text { breakthrough technologies }\end{array}$ \\
\hline $1-p_{y}$ & $\begin{array}{l}\text { Proportion of existing high-tech enterprises adopting } \\
\text { locking technologies }\end{array}$ \\
\hline
\end{tabular}

\subsection{WoO-EGT Model Building 3.3.1 WoO-EGT Model of RIPEvolution}

In building the WoO-EGT model of RIP evolution, the returns of High-tech Enterprises A and B are expressed by $\alpha$ and $\beta$, respectively. The return matrix is shown in Tab. 3 . Moreover, $\alpha_{i j}=\beta_{j i}, \forall i, j \in\{B, L\}$.

Table 3 Return matrix of RIP evolutionary game

\begin{tabular}{|} 
Table 3 Return matrix of RIP evolutionary game \\
\begin{tabular}{|c|c|c|c|}
\hline \multicolumn{2}{|c|}{ Strategy } & \multicolumn{2}{c|}{ High-tech Enterprise B } \\
\cline { 2 - 4 } & Breakthrough & Locking \\
\hline \multirow{2}{*}{$\begin{array}{c}\text { High-tech } \\
\text { Enterprise A }\end{array}$} & Breakthrough & $\left(\alpha_{B B}, \beta_{B B}\right)$ & $\left(\alpha_{B L}, \beta_{B L}\right)$ \\
\cline { 2 - 4 } & Locking & $\left(\alpha_{L B}, \beta_{L B}\right)$ & $\left(\alpha_{L L}, \beta_{L L}\right)$ \\
\hline
\end{tabular}
\end{tabular}

The utility functions of $S_{B}$ and $S_{L}$ are

$U^{B}=p \alpha_{B B}+(1-p) \alpha_{B L}$

$U^{L}=p \alpha_{L B}+(1-p) \alpha_{L L}$

The average utility $\Delta U$ of these two strategies is

$$
\Delta U=p U^{B}+(1-p) U^{L}
$$

The replicated dynamic equation of RIP is calculated according to Eqs. (1)-(3) as follows:

$$
F(p)=p(1-p)\left[\left(\alpha_{B B}+\alpha_{L L}-\alpha_{B L}-\alpha_{L B}\right) p+\alpha_{B L}-\alpha_{L L}\right]
$$

Given that $F(p)=0$, the three equilibrium solutions of the replication dynamic equation are as follows:

$$
\left\{\begin{array}{l}
p_{1}^{*}=0 \\
p_{2}^{*}=1 \\
p_{3}^{*}=\frac{\alpha_{L L}-\alpha_{B L}}{\alpha_{B B}+\alpha_{L L}-\alpha_{B L}-\alpha_{L B}}, 0<p_{3}^{*}<1
\end{array}\right.
$$

The stable state must be robust to small disturbances to achieve ESS. According to the ESS equilibrium robustness test, the three equilibrium solutions of Eq. (5) should meet $F^{\prime}(P)<0$.

\subsubsection{WoO-EGT Model of RIP Evolution for Existing High- tech Enterprises}

Strategies are selected when $\mathrm{WoO}$ is opened. The players in this case are existing enterprises (i.e., High-tech Enterprises A and B). According to the payoff function, the 
returns are gained by existing high-tech enterprises from the game (Tab. 4).

The replicated dynamic equation of the existing hightech enterprises is obtained according to Eq. (4).

$$
F\left(p_{y}\right)=\frac{\mathrm{d} p_{y}}{\mathrm{~d} t}=p_{y}\left(1-p_{y}\right)\left[A p_{y}+B\right]
$$

where $A=(1-\varphi)\left(R_{B}-C_{B}^{1}-C_{B}^{2}\right), B=\varphi\left(R_{B}-C_{B}^{1}-C_{B}^{2}\right)-$ $-\left(R_{L}-C_{L}^{2}\right)$. By taking the derivative of $F\left(p_{y}\right)$,

$$
F^{\prime}\left(p_{y}\right)=-3 A\left(p_{y}\right)^{2}+2(A-B) p_{y}+B
$$

Table 4 Return matrix of RIP evolutionary game of existing high-tech enterprises

\begin{tabular}{|c|c|c|c|}
\hline \multicolumn{2}{|c|}{ Strategy } & \multicolumn{2}{|c|}{ Existing High-tech Enterprise B } \\
\cline { 2 - 4 } $\begin{array}{c}\text { Existing High-tech } \\
\text { Enterprise A }\end{array}$ & Breakthrough & $R_{B}-C_{B}^{1}-C_{B}^{2}, R_{B}-C_{B}^{1}-C_{B}^{2}$ & $\varphi\left(R_{B}-C_{B}^{1}-C_{B}^{2}\right), R_{L}-C_{L}^{2}$ \\
\cline { 2 - 4 } & Locking & $R_{L}-C_{L}^{2}, \varphi\left(R_{B}-C_{B}^{1}-C_{B}^{2}\right)$ & $R_{L}-C_{L}^{2}, R_{L}-C_{L}^{2}$ \\
\hline
\end{tabular}

Table 5 Return matrix of RIP evolutionary game of new high-tech enterprises

\begin{tabular}{|c|c|c|c|}
\hline \multicolumn{2}{|c|}{ Strategy } & \multicolumn{2}{|c|}{ New High-tech Enterprise B } \\
\cline { 2 - 3 } \multirow{2}{*}{$\begin{array}{c}\text { New High-tech } \\
\text { Enterprise A }\end{array}$} & Breakthrough & $R_{B}-C_{B}^{1}-C_{B}^{2}, R_{B}-C_{B}^{1}-C_{B}^{2}$ & $\varphi\left(R_{B}-C_{B}^{1}-C_{B}^{2}\right), R_{L}-C_{L}^{1}-C_{L}^{2}$ \\
\cline { 2 - 4 } & Locking & $R_{L}-C_{L}^{1}-C_{L}^{2}, \varphi\left(R_{B}-C_{B}^{1}-C_{B}^{2}\right)$ & $R_{L}-C_{L}^{1}-C_{L}^{2}, R_{L}-C_{L}^{1}-C_{L}^{2}$ \\
\hline
\end{tabular}

\subsubsection{WoO-EGT Model of RIP Evolution for New High-tech Enterprises}

In this case, the players are new enterprises (i.e., Hightech Enterprises A and B). The returns are gained by new high-tech enterprises from the game (Tab. 5).

The replicated dynamic equation of the new high-tech enterprises is obtained according to Eq. (4).

$F\left(p_{x}\right)=\frac{\mathrm{d} p_{x}}{\mathrm{~d} t}=p_{x}\left(1-p_{x}\right)\left[A p_{x}+B\right]$

where $A=(1-\varphi)\left(R_{B}-C_{B}^{1}-C_{B}^{2}\right), B=\varphi\left(R_{B}-C_{B}^{1}-C_{B}^{2}\right)-$. $-\left(R_{L}-C_{L}^{1}-C_{L}^{2}\right)$. By taking the derivative of $F\left(p_{x}\right)$,

$F^{\prime}\left(p_{x}\right)=-3 A\left(p_{x}\right)^{2}+2(A-B) p_{x}+B$

\subsection{Matlab Simulation Design}

The mechanisms of relevant factors influencing RIP are dynamically simulated in Matlab. The dynamic evolutionary trajectory of the RIPs of high-tech enterprises is demonstrated by numerical simulation when $\mathrm{WoO}$ is opened, as in the case of changing initial conditions or decision parameters.

The influences of returns and initial proportions $\left(p_{x}, p_{y}\right)$ of locking and breakthrough technologies on the RIPs of high-tech enterprises are investigated. The technology returns are set according to the propositional conditions. The initial proportions $p_{x}$ and $p_{y}$ are $0.1,0.3,0.5,0.7$, and 0.9. In addition, given that $X=\pi_{B}=R_{B}-C_{B}^{1}-C_{B}^{2}$, $Y=\pi_{L}^{1}=R_{L}-C_{L}^{1}-C_{L}^{2}, Z=\pi_{L}^{2}=R_{L}-C_{L}^{2}$, and $Y<Z$. The program code is written with time $T$ in the horizontal axis and group proportion $p_{x}$ or $p_{y}$ in the vertical axis.

\section{RESULT ANALYSIS AND DISCUSSION}

\subsection{ESS Analysis of Existing High-tech Enterprises}

Given that $F\left(p_{y}\right)$, three possible stable state points can be determined.

$$
\left\{\begin{array}{l}
p_{y}^{1 *}=0 \\
p_{y}^{2 *}=1 \\
p_{y}^{3 *}=-\frac{B}{A}, 0<p_{y}^{3 *}<1
\end{array}\right.
$$

According to the stability theorem of differential equation $F^{\prime}\left(p_{y}\right)<0$, the following propositions can be obtained:

\section{Proposition 1.}

When $R_{B}-C_{B}^{1}-C_{B}^{2}<\varphi\left(R_{B}-C_{B}^{1}-C_{B}^{2}\right)<R_{L}-C_{L}^{2}$, the ESS is $p_{y}^{1 *}=0$.

Proof: In Eq. (7),

$$
\left\{\begin{array}{l}
F^{\prime}(0)=\varphi\left(R_{B}-C_{B}^{1}-C_{B}^{2}\right)-\left(R_{L}-C_{L}^{2}\right)<0 \\
F^{\prime}(1)=-\left[\left(R_{B}-C_{B}^{1}-C_{B}^{2}\right)-\left(R_{L}-C_{L}^{2}\right)\right]>0 \\
F^{\prime}\left(-\frac{B}{A}\right)=-\frac{B(A+B)}{A}>0,-\frac{B}{A}<0
\end{array}\right.
$$

and $p_{y}^{1 *}=0$ is the ESS.

Regardless of the technology to be adopted by the opponent, when the returns of the breakthrough technology are less than those of the locking technology (excluding $C^{1}$ ), a rationally existing high-tech enterprise will continue to carry out incremental innovation processes. The result indicates that dynamic evolution can be represented by all existing high-tech enterprises continuously carrying out incremental innovation processes. Even if minimal variations exist for RIP, the high-tech enterprises will soon 
disappear. However, as long as not all high-tech enterprises do not initially implement RIP, the incremental innovations will be considered in the long term until dynamic changes are realized. The phase diagram is shown in Fig. 1.

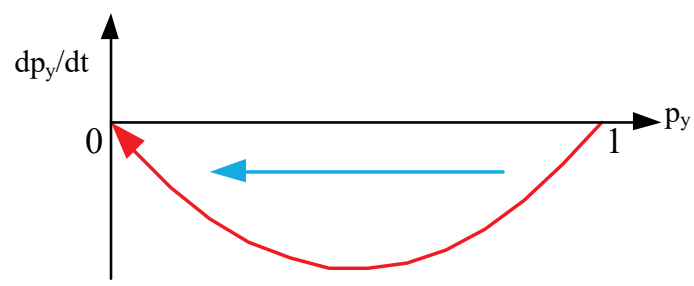

Figure 1 Phase diagram of proposition 1

\section{Proposition 2.}

When $R_{L}-C_{L}^{2}<R_{B}-C_{B}^{1}-C_{B}^{2}<\varphi\left(R_{B}-C_{B}^{1}-C_{B}^{2}\right)$, the $\mathrm{ESS}$ is $p_{y}^{2 *}=1$.

Proof: In Eq. (7),

$$
\left\{\begin{array}{l}
F^{\prime}(0)=\varphi\left(R_{B}-C_{B}^{1}-C_{B}^{2}\right)-\left(R_{L}-C_{L}^{2}\right)>0 \\
F^{\prime}(1)=-\left[\left(R_{B}-C_{B}^{1}-C_{B}^{2}\right)-\left(R_{L}-C_{L}^{2}\right)\right]<0 \\
F^{\prime}\left(-\frac{B}{A}\right)=-\frac{B(A+B)}{A}>0
\end{array}\right.
$$

and $p_{y}^{2 *}=1$ is the ESS.

Regardless of the technology to be adopted by the opponent, when the returns of the breakthrough technology adopted are higher than those of the locking technology (excluding $C^{1}$ ), a rationally existing high-tech enterprise will abandon locking technologies to implement RIP. The result indicates that dynamic evolution can be represented by all high-tech enterprises gradually adopting RIP. The phase diagram is shown in Fig. 2.

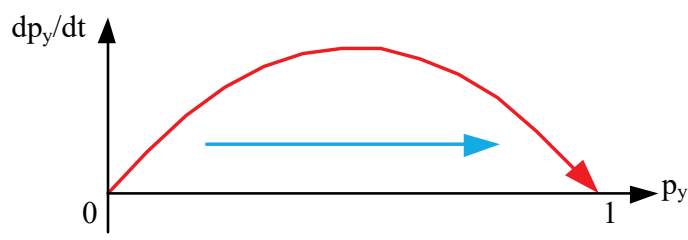

Figure 2 Phase diagram of proposition 2

\section{Proposition 3.}

When $R_{B}-C_{B}^{1}-C_{B}^{2}<R_{L}-C_{L}^{2}<\varphi\left(R_{B}-C_{B}^{1}-C_{B}^{2}\right)$, the ESS is $p_{y}^{3 *}=\frac{\varphi\left(R_{B}-C_{B}^{1}-C_{B}^{2}\right)-\left(R_{L}-C_{L}^{2}\right)}{\varphi\left(R_{B}-C_{B}^{1}-C_{B}^{2}\right)-\left(R_{B}-C_{B}^{1}-C_{B}^{2}\right)}$.

Proof: In Eq. (7),

$$
\left\{\begin{array}{l}
F^{\prime}(0)=\varphi\left(R_{B}-C_{B}^{1}-C_{B}^{2}\right)-\left(R_{L}-C_{L}^{2}\right)>0 \\
F^{\prime}(1)=-\left[\left(R_{B}-C_{B}^{1}-C_{B}^{2}\right)-\left(R_{L}-C_{L}^{2}\right)\right]>0 \\
F^{\prime}\left(-\frac{B}{A}\right)=-\frac{B(A+B)}{A}<0,0<-\frac{B}{A}<1
\end{array}\right.
$$

and $p_{y}^{3 *}=\frac{\varphi\left(R_{B}-C_{B}^{1}-C_{B}^{2}\right)-\left(R_{L}-C_{L}^{2}\right)}{\varphi\left(R_{B}-C_{B}^{1}-C_{B}^{2}\right)-\left(R_{B}-C_{B}^{1}-C_{B}^{2}\right)}$ is the ESS.

When the returns of the locking technology (excluding $C^{1}$ ) are higher than those of the breakthrough technology adopted by only one game side, but the returns are less than those of the breakthrough technology adopted by both game sides, the variation will involve a small number of high-tech enterprises abandoning the locking technology to implement RIP. The variant high-tech enterprises will increase gradually until $p_{y}^{3 *}$. If the proportion exceeds $p_{y}^{3 *}$, or if all high-tech enterprises adopt the breakthrough technology, then minimal variations of incremental innovation processes will spread among them. The phase diagram is shown in Fig. 3.

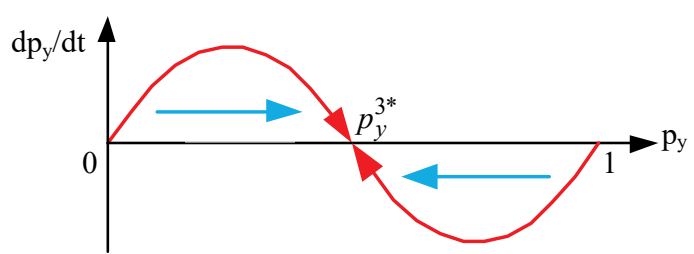

Figure 3 Phase diagram of proposition 3

\subsection{ESS Analysis of New High-tech Enterprises}

Given that $F\left(p_{x}\right)=0$, three possible stable state points can be determined.

$\left\{\begin{array}{l}p_{x}^{1 *}=0 \\ p_{x}^{2 *}=1 \\ p_{x}^{3 *}=-\frac{B}{A}, 0<p_{x}^{3 *}<1\end{array}\right.$

According to the stability theorem of differential equation, the following propositions can be obtained:

Proposition 4.

When $R_{B}-C_{B}^{1}-C_{B}^{2}<\varphi\left(R_{B}-C_{B}^{1}-C_{B}^{2}\right)<R_{L}-C_{L}^{1}-C_{L}^{2}$, the ESS is $p_{x}^{1 *}=0$.

Proof: In Eq. (9),

$$
\left\{\begin{array}{l}
F^{\prime}(0)=\varphi\left(R_{B}-C_{B}^{1}-C_{B}^{2}\right)-\left(R_{L}-C_{L}^{1}-C_{L}^{2}\right)<0 \\
F^{\prime}(1)=-\left[\left(R_{B}-C_{B}^{1}-C_{B}^{2}\right)-\left(R_{L}-C_{L}^{1}-C_{L}^{2}\right)\right]>0 \\
F^{\prime}\left(-\frac{B}{A}\right)=-\frac{B(A+B)}{A}>0,-\frac{B}{A}<0
\end{array}\right.
$$

and $p_{x}^{1 *}=0$ is the ESS.

Regardless of the technology to be adopted by the opponent, when the returns of the breakthrough technology are less than those of the locking technology (including $C^{1}$ ), a rationally new high-tech enterprise will select the locking technology to implement incremental innovation. The result indicates that dynamic evolution can be represented by all new high-tech enterprises implementing 
incremental innovation. Even if minimal variations exist for RIP, these new high-tech enterprises will soon disappear. However, as long as not all new high-tech enterprises do not initially implement RIP, the incremental innovations will be considered in the long term until dynamic changes are realized. The phase diagram is shown in Fig. 4.

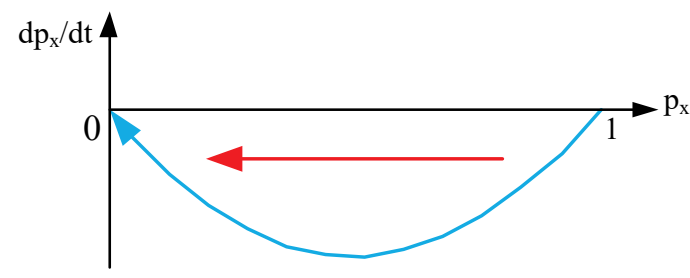

Figure 4 Phase diagram of proposition 4

\section{Proposition 5.}

When $R_{L}-C_{L}^{1}-C_{L}^{2}<R_{B}-C_{B}^{1}-C_{B}^{2}<\varphi\left(R_{B}-C_{B}^{1}-C_{B}^{2}\right)$, the ESS is $p_{x}^{2^{*}}=1$.

Proof: In Eq. (9),

$$
\left\{\begin{array}{l}
F^{\prime}(0)=\varphi\left(R_{B}-C_{B}^{1}-C_{B}^{2}\right)-\left(R_{L}-C_{L}^{2}\right)>0 \\
F^{\prime}(1)=-\left[\left(R_{B}-C_{B}^{1}-C_{B}^{2}\right)-\left(R_{L}-C_{L}^{1}-C_{L}^{2}\right)\right]<0 \\
F^{\prime}\left(-\frac{B}{A}\right)=-\frac{B(A+B)}{A}>0
\end{array}\right.
$$

and $p_{x}^{2^{*}}=1$ is the ESS.

Regardless of the strategy to be adopted by the opponent, when the returns of the breakthrough technology are higher than those of the locking technology (including $C^{1}$ ), a rationally new high-tech enterprise will implement RIP. The result indicates that evolution can be represented by all new high-tech enterprises gradually spreading incremental innovation. The phase diagram is shown in Fig. 5 .

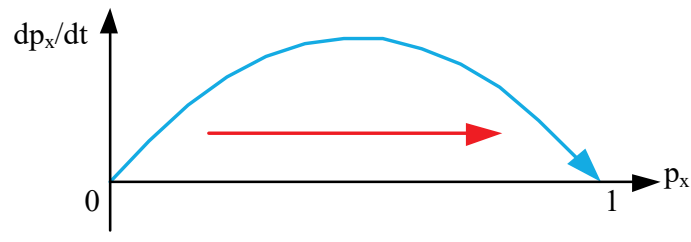

Figure 5 Phase diagram of proposition 5

\section{Proposition 6.}

When $R_{B}-C_{B}^{1}-C_{B}^{2}<R_{L}-C_{L}^{1}-C_{L}^{2}<\varphi\left(R_{B}-C_{B}^{1}-C_{B}^{2}\right)$, the ESS is $p_{x}^{3 *}=\frac{\varphi\left(R_{B}-C_{B}^{1}-C_{B}^{2}\right)-\left(R_{L}-C_{L}^{1}-C_{L}^{2}\right)}{\varphi\left(R_{B}-C_{B}^{1}-C_{B}^{2}\right)-\left(R_{B}-C_{B}^{1}-C_{B}^{2}\right)}$

Proof: In Eq. (9),

$$
\left\{\begin{array}{l}
F^{\prime}(0)=\varphi\left(R_{B}-C_{B}^{1}-C_{B}^{2}\right)-\left(R_{L}-C_{L}^{2}\right)>0 \\
F^{\prime}(1)=-\left[\left(R_{B}-C_{B}^{1}-C_{B}^{2}\right)-\left(R_{L}-C_{L}^{2}\right)\right]>0 \\
F^{\prime}\left(-\frac{B}{A}\right)=-\frac{B(A+B)}{A}<0,0<-\frac{B}{A}<1
\end{array}\right.
$$

and $p_{x}^{3 *}=\frac{\varphi\left(R_{B}-C_{B}^{1}-C_{B}^{2}\right)-\left(R_{L}-C_{L}^{1}-C_{L}^{2}\right)}{\varphi\left(R_{B}-C_{B}^{1}-C_{B}^{2}\right)-\left(R_{B}-C_{B}^{1}-C_{B}^{2}\right)}$ is the ESS.

When the returns of the locking technology (including $C^{1}$ ) are higher than those of the breakthrough technology adopted by only one game side, but the returns are less than those of the breakthrough technology adopted by both game sides, the variation will involve a small number of high-tech enterprises implementing RIP. The variant hightech enterprises will increase gradually until $p_{x}^{3 *}$. If the proportion of high-tech enterprises implementing RIP exceeds $p_{x}^{3 *}$, or if minimal variations of incremental innovation spread among enterprises because of the profits brought forth by the breakthrough technology. The phase diagram is shown in Fig. 6.

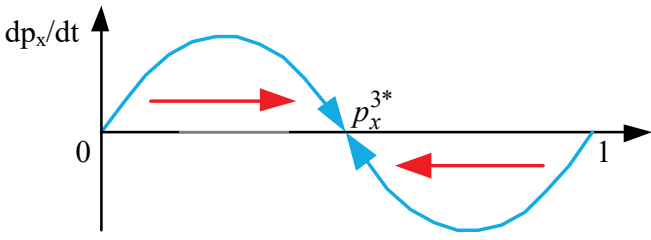

Figure 6 Phase diagram of proposition 6

\subsection{Dynamic Evolution Simulation of the Locking Technology}

According to Propositions 1 and 3, the conditions are $Z=6, X=2.5, \varphi=2$ and $Y=5, X=1.5, \varphi=2$. The simulation result is shown in Fig. 7.

Fig. 7 presents the evolution path of existing and new high-tech enterprises with different initial points relative to the equilibrium points $p_{y}^{1 *}=0$ and $p_{x}^{1 *}=0$, respectively. The smaller the proportion is for high-tech enterprises to initially select the breakthrough technology, the slower will these enterprises approach the equilibrium point 0 , and vice versa.

\subsection{Dynamic Evolution Simulation of the Breakthrough Technology}

According to Propositions 2 and 5, the conditions are $Z=2.5, X=5, \varphi=1.5$ and $Y=1.5, X=2.5, \varphi=2$. The simulation result is shown in Fig. 8.

Fig. 8 presents the evolution path of existing and new high-tech enterprises with different initial points relative to the equilibrium point $p_{y}^{2^{*}}=1$ and $p_{x}^{2^{*}}=1$, respectively. The smaller the proportion is for high-tech enterprises to initially select the breakthrough technology, the faster will these enterprises approach the equilibrium point 1 , and vice versa. 

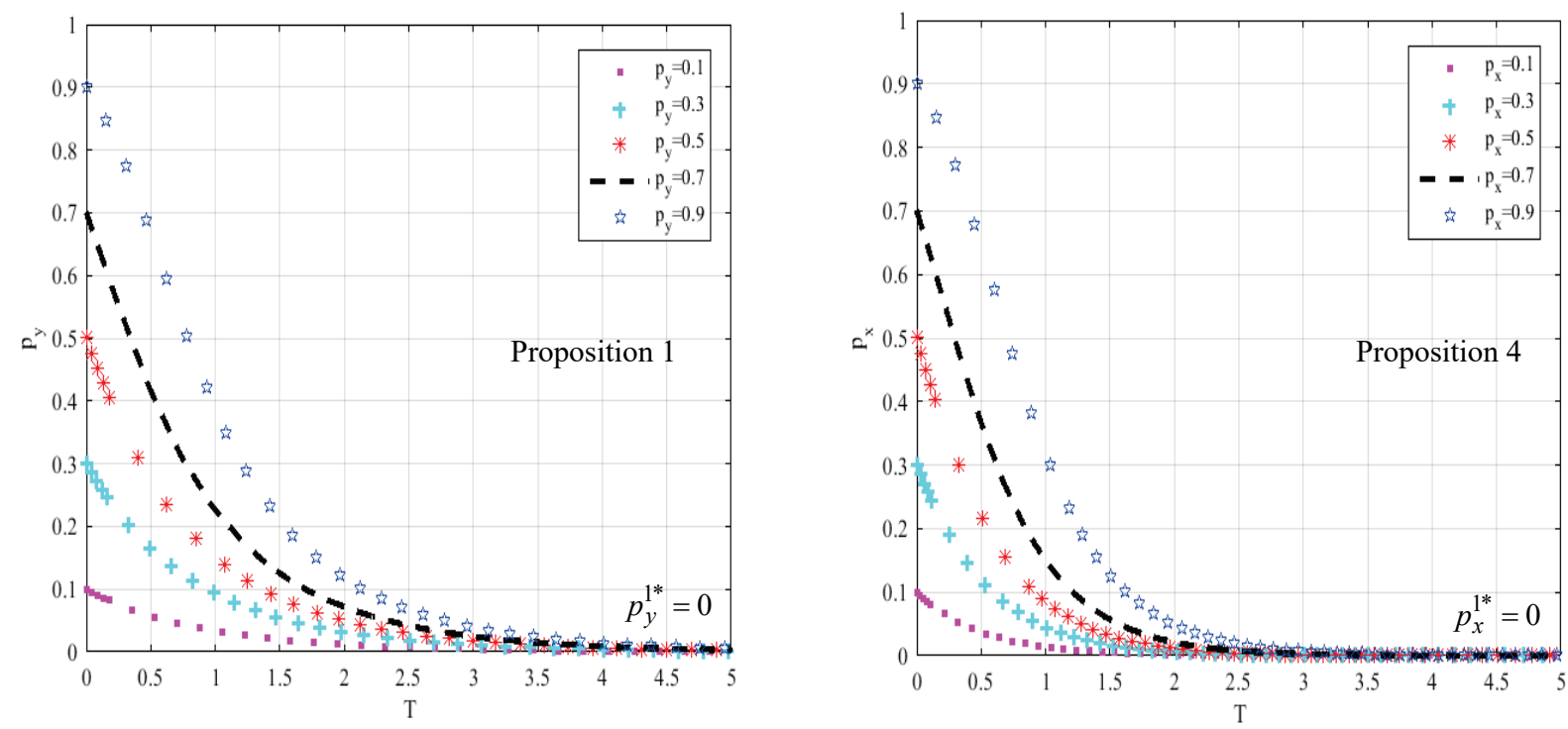

Figure 7 Effect of initial proportion of selecting breakthrough technology on evolution results $\left(p^{1 *}=0\right)$
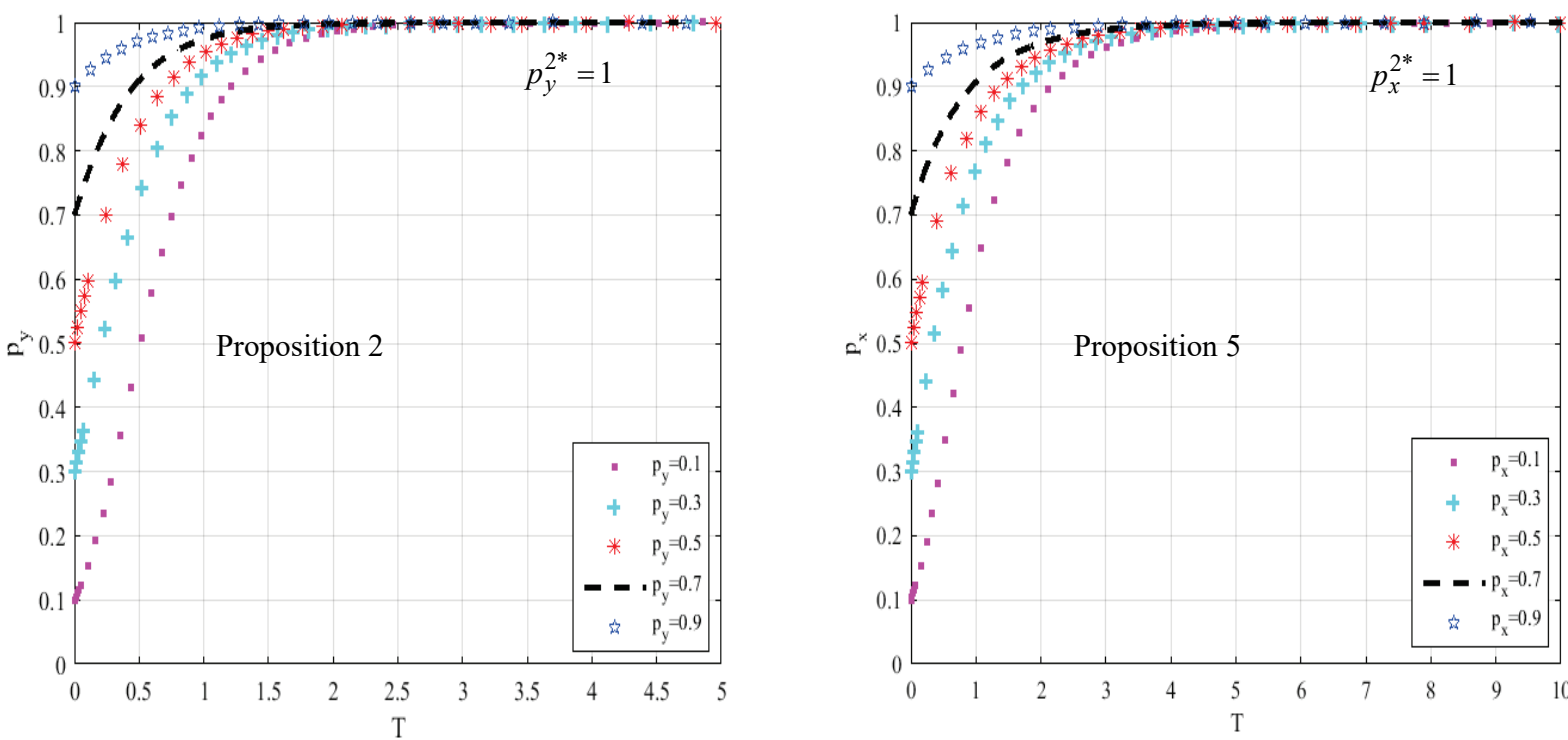

Figure 8 Effect of initial proportion of selecting breakthrough technology on evolution results $\left(p^{2 *}=1\right)$
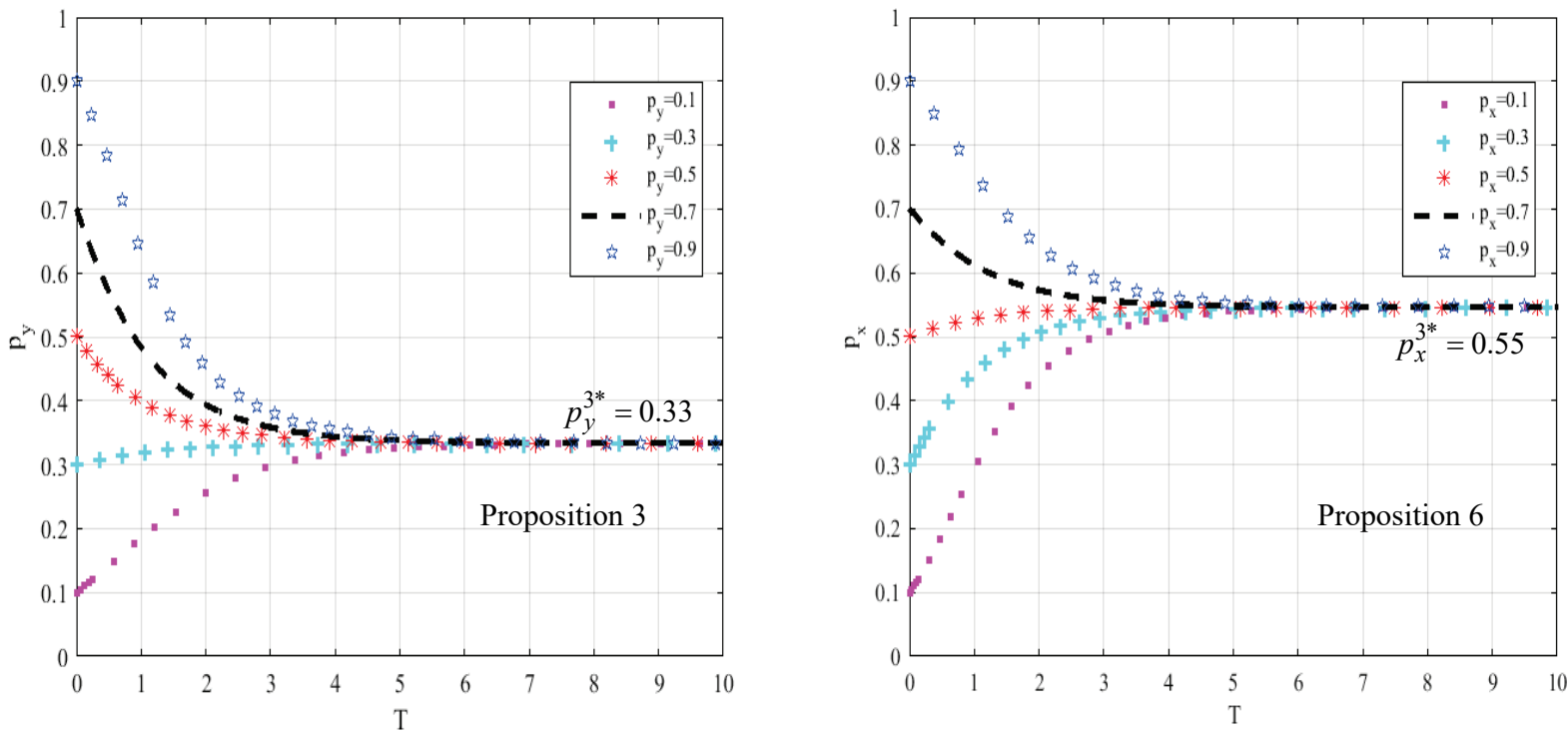

Figure $9 \mathrm{Effect}$ of initial proportion of selecting breakthrough technology on evolution results $\left(p^{3^{*}}=-\frac{B}{A}\right)$ 


\subsection{Dynamic Evolution Simulation of the Breakthrough and Locking Technologies}

According to Propositions 3 and 6, the conditions are $Z=5, X=5, \varphi=2.5$ and $Y=5, X=5, \varphi=2.5$. The simulation result is shown in Fig. 9.

Fig. 9 presents the evolution path of existing and new high-tech enterprises with different initial points relative to the equilibrium point $p^{3 *}$, where $p_{y}^{3^{*}}=0.33$, or $p_{x}^{3^{*}}=0.55$ If the proportion of existing high-tech enterprises initially selecting the breakthrough technology is $p_{y}<p_{y}^{3^{*}}$ (or $p_{x}<p_{x}^{3^{*}}$ for new high-tech enterprises), then $p_{y}$ (or $p_{x}$ ) continues to increase until $p_{y}^{3^{*}}$ (or $p_{x}^{3^{*}}$ ), and vice versa. In addition, the greater the value of $\left|p_{y}-p_{y}^{3^{*}}\right|$ (or $\left.\left|p_{x}-p_{x}^{3^{*}}\right|\right)$ is, the faster the high-tech enterprises will approach the equilibrium point $p_{y}^{3^{*}}$ (or $p_{x}^{3^{*}}$ ), and vice versa.

\section{CONCLUSIONS}

To overcome the research gap regarding the impact mechanism and influencing factors of the dynamic evolution of RIP among high-tech enterprises, the WoOEGT model of the dynamic evolution of RIP was built by combining $\mathrm{WoO}$ and EGT. This study analyzed the evolution results of the RIPs of existing and new high-tech enterprises. Then, the effect of the returns and initial proportion of breakthrough technologies was dynamically simulated in Matlab. The following conclusions were obtained:

(1) WoO is the best opportunity for high-tech enterprises to implement RIP, and this finding has been verified by the WoO-EGT model. Under the WoO context, existing technologies are limited to incremental innovation. The three evolution results on the RIPs of high-tech enterprises are as follows: only locking technology in the market, only breakthrough technology in the market, and coexistence of locking technology and breakthrough technology in the market. The breakthrough technologies of the latter two evolution results are in accord with market conditions, and RIP can be successfully achieved.

(2) The decisive role of the returns of breakthrough technology on the evolution results of RIP can be deeply analyzed by using the WoO-EGT model and its simulation in Matlab. Regardless of the technology to be adopted by high-tech enterprises, when the returns of breakthrough technology are higher than those of locking technology, both existing and new high-tech enterprises will eventually select the breakthrough technology to implement RIP, and vice versa. In addition, when the returns of locking technology are higher than those of breakthrough technology adopted by only one game side, but the returns are less than those of breakthrough technology adopted by both game sides, the high-tech enterprises adopting locking technology and breakthrough technology can separately realize certain proportions of the market.

(3) The influence of the initial proportion of breakthrough technology on the evolution speed of RIP can be dynamically detected on the basis of WoO-EGT model and its Matlab simulation. The farther the initial proportion point of breakthrough technology from the ESS equilibrium point, the faster the existing and new high-tech enterprises will approach the ESS equilibrium point. By contrast, the closer the initial proportion point is to the ESS equilibrium point, the slower the existing and new hightech enterprises will approach the ESS equilibrium point.

The application of the WoO-EGT model and its Matlab simulation to the dynamic evolution analysis of RIPs of high-tech enterprises can expound the three results of dynamic evolution and the impact mechanism of the returns and initial proportion of breakthrough technology, which is of great importance to high-tech enterprises implementing RIP in the WoO context. The WoO-EGT model can effectively analyze the RIPs of high-tech enterprises. Apart from helping overcome the deficiencies of the static model, new decision-making ideas and methods for RIP analysis can be achieved, thus contributing to the improvement of the success rates of radical innovation.

Despite the new findings, constraints related to the payoff function have been observed. The return function of RIP in this study has taken into account technology cost, production cost, and the first-move dominance coefficient. However, other factors can be included, such as government subsidies. In the future, the integration of government subsidies in the payoff function can further enhance the impact mechanism results derived from the constructed WoO-EGT model in this study.

\section{Acknowledgement}

This study was supported by the Ministry of Education of Humanities and Social Science Project under Grant No. 18YJA630086.

\section{REFERENCES}

[1] Sheng, M. L. \& Chien, I. (2016). Rethinking organizational learning orientation on radical and incremental innovation in high-tech firms. Journal of Business Research, 69(6), 23022308. https://doi.org/10.1016/j.jbusres.2015.12.046

[2] Onufrey, K. \& Bergek, A. (2015). Self-reinforcing mechanisms in a multi-technology industry: Understanding sustained technological variety in a context of path dependency. Industry \& Innovation, 22(6), 523-551. https://doi.org/10.1080/13662716.2015.1100532

[3] Durand, R. \& Vergne, J. P. (2010). The missing link between the theory and empirics of path dependence: Conceptual clarification, testability issue, and methodological implications. Journal of Management Studies, 47(4), 736759. https://doi.org/10.1111/j.1467-6486.2009.00913.x

[4] Peneder, M. \& Woerter, M. (2014). Competition, R\&D and innovation: Testing the inverted-U in a simultaneous system. Journal of Evolutionary Economics, 24(3), 653-687. https://doi.org/10.1007/s00191-013-0310-z

[5] Xu, J. \& Ni, T. (2017). Integrated technological paradigmbased soft paths towards sustainable development of small hydropower. Renewable \& Sustainable Energy Reviews, 70, 623-634. https://doi.org/10.1016/j.rser.2016.11.021

[6] Kim, D. H., Lee, H., \& Kwak, J. (2017). Standards as a driving force that influences emerging technological trajectories in the converging world of the Internet and things: An investigation of the M2M/IoT patent network. Research Policy, 46(7), 1234-1254 https://doi.org/10.1016/j.respol.2017.05.008

[7] Perra, D. B., Sidhu, J. S., \& Volberda, H. W. (2017). How 
do established firms produce breakthrough innovations? Managerial Identity-Dissemination discourse and the creation of novel Product-Market solutions: Established firms and breakthrough innovations. Journal of Product Innovation Management, 34(4), 509-525. https://doi.org/10.1111/jpim.12390

[8] Isaksen, A. (2015). Industrial development in thin regions: Trapped in path extension? Journal of Economic Geography, 15(3), 585-600. https://doi.org/10.1093/jeg/lbu026

[9] Schienstock, G. (2007). From path dependency to path creation: Finland on its way to the knowledge-based economy. Current Sociology, 55(1), 92-109. https://doi.org/10.1177/0011392107070136

[10] Belas, J., Ivanova, E., Rozsa, Z., \& Schonfeld, J. (2018). Innovations in SME segment: Important factors and differences in the approach by size and age of the company. Transformations in Business \& Economics, 17(3), 55-71.

[11] Aparicio, M. J. V., Llaguno, M. M., \& Garcia, M. I. (2018). Communications obligations for Spanish enterprises receiving state R\&D plus its grants. DYNA, 93(3), 268-271.

[12] Tsiapa, M., Kallioras, D., \& Tzeremes, N. G. (2018). The role of path-dependence in the resilience of EU regions. European Planning Studies, 26(6), 1099-1120. https://doi.org/10.1080/09654313.2018.1458284

[13] Lawrence, A., Sovacool, B., \& Stirling, A. (2016). Nuclear energy and path dependence in Europe's 'Energy union': Coherence or continued divergence? Climate Policy, 16(5), 622-641. https://doi.org/10.1080/14693062.2016.1179616

[14]Cecere, G., Corrocher, N., Gossart, C., \& Ozman, M. (2014). Lock-in and path dependence: An evolutionary approach to eco-innovations. Journal of Evolutionary Economics, 24(5), 1037-1065. https://doi.org/10.1007/s00191-014-0381-5

[15] Crouch, C. \& Farrell, H. (2004). Breaking the path of institutional development? Alternatives to the new determinism. Rationality and Society, 16(1), 5-43. https://doi.org/10.1177/1043463104039874

[16] Parida, V., Patel, P.C., Frishammar, J., \& Wincent, J. (2017). Managing the front-end phase of process innovation under conditions of high uncertainty. Quality \& Quantity, 51(5), 1983-2000. https://doi.org/10.1007/s11135-016-0376-4

[17] Schreyögg, G. \& Sydow, J. (2011). Organizational path dependence: A process view. Organization Studies, 32(3), 321-335.https://doi.org/10.1177/0170840610397481

[18] Sierra, L. A., Yepes, V., García-Segura, T., \& Pellicer, E. (2018). Bayesian network method for decision-making about the social sustainability of infrastructure projects. Journal of Cleaner Production, 176, 521-534. https://doi.org/10.1016/j.jclepro.2017.12.140

[19] Kachouie, R., Sedighadeli, S., Khosla, R., \& Chu, M.T. (2014). Socially assistive robots in elderly care: A MixedMethod systematic literature review. International Journal of Human-Computer Interaction, 30(5), 369-393. https://doi.org/10.1080/10447318.2013.873278

[20] Kao, C. \& Hwang, S. N. (2014). Multi-period efficiency and Malmquist productivity index in two-stage production systems. European Journal of Operational Research, 232(3), 512-521. https://doi.org/10.1016/j.ejor.2013.07.030

[21] Seiford, L. M. \& Thrall, R. M. (1990). Recent developments in DEA: The mathematical programming approach to frontier analysis. Journal of Econometrics, 46(1-2), 7-38. https://doi.org/10.1016/0304-4076(90)90045-U

[22] Stake, R. E. (1978). The case study method in social inquiry. Educational Researcher, 7(2), 5-8. https://doi.org/10.3102/0013189X007002005

[23] Thrane, S., Blaabjerg, S., \& Møller, R. H. (2010). Innovative path dependence: Making sense of product and service innovation in path dependent innovation processes. Research Policy, 39(7), 932-944. https://doi.org/10.1016/j.respol.2010.04.003

[24] Garay, J., Cressman, R., Móri, T. F., \& Varga, T. (2018). The
ESS and replicator equation in matrix games under time constraints. Journal of Mathematical Biology, 76(7), 19511973.https://doi.org/10.1007/s00285-018-1207-0

[25] Robledo1, M. E., Obregón, L. G., \& Velázquez, C. (2018). Simulation of a compressible powder flow under oscillatory shear stress modelled as a non-Linear fluid by using an explicit solution method. Journal of Engineering Science and Technology Review, 11(4), 84-90.

[26] Pol, J. V. D. \& Rameshkoumar, J. P. (2018). The coevolution of knowledge and collaboration networks: The role of the technology life-cycle. Scientometrics, 114(1), 307-323 https://doi.org/10.1007/s11192-017-2579-4

[27] Seidel, V. P., Langner, B., \& Sims, J. (2017). Dominant communities and dominant designs: Community-Based innovation in the context of the technology life cycle. Social Science Electronic Publishing, 15(2), 220-241. https://doi.org/10.1177/1476127016653726

[28] Silva, G. M., Styles, C., \& Lages, L. F. (2017). Breakthrough innovation in international business: The impact of techinnovation and market-innovation on performance. International Business Review, 26(2), 391-404. https://doi.org/10.1016/j.ibusrev.2016.10.001

\section{Contact information:}

Zhen ZHANG, PhD (Corresponding author)

School of Management, Wuhan University of Technology, Room 501, No. 122 Luoshi Road,

Hongshan District, Wuhan City, Hubei Province, China

E-mail: zhangzhenquanquan@whut.edu.cn

Jintian YU, PhD

School of Management, Wuhan University of Technology, Room 501, No. 122 Luoshi Road,

Hongshan District, Wuhan City, Hubei Province, China

E-mail: yjt8188@126.com 